\title{
Research Paper: \\ Psychometric Characteristics and Factor Analysis of the Persian Version of Couples Satisfaction Index
}

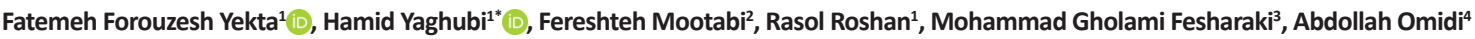

1. Department of Clinical Psychology, Faculty of Humanities, Shahed University, Tehran, Iran.

2. Family Research Institute, University of Shahid Beheshti, Tehran, Iran.

3. Department of Biostatistics, Faculty of Medical Sciences, Tarbiat Modares University, Tehran, Iran.

4. Department of Clinical Psychology, Faculty of Medicine, Kashan University of Medical Sciences, Tehran, Iran.

Funding: See Page 55

(c) Copyright: The Author(s)

Article info:

Received: 26 November 2016

Accepted: 28 March 2016

Available Online: 01 May 2017

Keywords:

Marital relationships, Marital satisfaction, Reliability and validity, Factor analysis

\begin{abstract}
Background: The concept of couples' satisfaction is one's subjective evaluation of marital relationship and the level of perceived happiness from this relationship. Couples Satisfaction Index (CSI) is a self-report measure to assess marital satisfaction. This study aims to evaluate the psychometric characteristics of the Persian version of CSI in a non-clinical sample.

Materials and Methods: Factor analysis, translation, structural, convergent validity, and reliability of this index were investigated in 150 married students of Tehran and Shahed Universities recruited by convenience sample method.

Results: According to the results of the exploratory factor analysis, four factors of "marital happiness", "warmth of the relationship", "being together", and "right choice" were identified in the Persian version of CSI. The specifications of exploratory factor analysis were good. The results of the confirmatory factor analysis showed that four factors of the CSI are more valid and reliable. The reliability of the index was 0.96 determined by Cronbach $\alpha$. The convergence between this index and Locke-Wallace Marital Adjustment Test (MAT) was calculated to be 0.9.
\end{abstract}

Conclusion: Results indicate that Persian version of CSI has appropriate psychometric characteristics. Therefore, this measure can be confidently used in this field of research.

\section{Introduction}

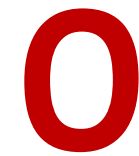

ne of the most intimate relationships is the marriage one. For many couples, marriage is the main source of adult intimacy, getting support, companionship, and per- sonal growth [1]. Experiencing a satisfactory romantic relationship is one of the strongest predictors of life satisfaction and well-being [2, 3], in other words, higher physical health and longer lifespan [4-7]. Couples who suffer from distressed relationships are susceptible to mood and anxiety disorders and drug abuse [8, 9].

* Corresponding Author:

Hamid Yaghubi, PhD

Address: Department of Clinical Psychology, Faculty of Humanities, Shahed University, Tehran, Iran.

E-mail: yaghubi@shahed.ac.ir 
Moreover, the perceived marital satisfaction is a predictor of relationship breakdown that is associated with one's psychological well-being $[10,11]$. The concept of relationship satisfaction has become a main objective in relationship research as well as couple therapy literature and is the basis for our understanding of how relationships or marriages work. There is a conceptual confusion in this felid though and a large number of terms, such as satisfaction, adjustment, success, happiness, companionship have been used in literature. Therefore, these terms tend to be used interchangeably [12].

This article focuses on a partner's subjective evaluation of a romantic relationship, thus we prefer the term relationship satisfaction and in particular marital satisfaction. Marital satisfaction is a situation in which the husband and wife are happy and satisfied with their marriage and being with each other [13]. Currently, satisfaction with marital relationship is assessed by self-report scales. Although, a large body of literature support the structural validity of these scales [13], they have never been systematically exposed to an analysis in item-level in order to evaluate their current level of precision. Given the widespread use of these scales and its key role in relationship literature, it seems necessary to have a critical look at the quality of marital satisfaction scales and their accuracy. Funk and Rogge believed that existing scales of relationship quality have significant measurement errors with negative impact on research outcomes that reduce their power, and consequently affect the development of the theoretical scope [14].

They used Item Response Theory (IRT) for assessing information quality that provide highly valid marital satisfaction scales. Their results indicate that existing scales are not accurate enough and do not provide much expected information, and many of their items increase the variance of error in measuring marital satisfaction. IRT is a method that can determine the accuracy of the items and the amount of information about a latent construct such as marital satisfaction. Accordingly, Funk and Rogge developed Couples Satisfaction Index (CSI) using the principal components analysis based on IRT [14]. In addition, the results indicate that some items of DAS and Marital Adjustment Test (MAT) scales are communicational concepts. Since resultant variables such as marital satisfaction might be infected with manipulated variables such as communication skills, and the results may be artificially increased, this subject is important in marital therapy studies.

To avoid this problem, communicational items of CSI scale were eliminated with accurate screening. That way a new marital satisfaction index with three versions (32, 16, or 4 items) was developed for different applications (from couple therapy studies that require more detailed 32-item scale to national surveys requiring the brief 4-item version). These scales have a higher degree of accuracy and ability to assess marital satisfaction than other existing scales. At the same time, they have good convergent and construct validity [14]. Since accurate scales are required for measuring marital satisfaction in Iranian studies, and CSI has not been validated in Iran yet, this paper evaluated psychometric characteristics of 32-item version of this measure.

\section{Materials and Methods}

\subsection{Study participants}

The statistical population included all married students living in dormitories of Tehran (80\%) and Shahed $(20 \%)$ universities in 2016-2017. Eligible individuals were married students aged 18 years or older. The sample consisted of 150 students. The sample size was calculated based on 3 to 15 subjects for each variable for CSI-32 [15]. They were selected by convenience sampling method, including 104 (69\%) women, and 46 (31\%) men. Their age ranged from 18 to 48 years (Mean=27 y). Nearly half of the participants (49\%) were undergraduates or had lower degrees, and the other half were graduate and postgraduate students. About $80 \%$ of the participants were experiencing their first five years of married life and most of them (68\%) had no children.

\subsection{Study procedure}

In order to use Persian version of CSI in Iranian society, after preparing the original version of scale that was freely available in web for research use [16], the scale was translated from English to Persian and its translation accuracy was discussed with three psychology professors who approved face validity of the scale. In the next step, the approved version was given to two translators (a psychologist fluent in both Farsi and English and an English specialist familiar with the psychology texts) who had not seen the original English text to retranslate it from Persian to English (reverse translation). After comparing the retranslated version with the original text of the scale, the mismatches were resolved. In a preliminary study, 5 people responded to the questionnaire to investigate fluency of translation and its difficulty for Persian people. None of items was omitted in this evaluation. 
To investigate psychometric characteristics and factor analysis of Persian version of CSI after obtaining permission from relevant authorities, the married students in dormitories of Tehran and Shahed universities were visited. The students were asked to answer the questionnaire if they would like. There was no rejection rate in this study. The researcher also participated in the meeting to explain about how to respond to questionnaire items and the confidentiality of their information. There was no time limit for completing the questionnaires. In order to assure the subjects that their information will be kept confidential, the questionnaires were anonymous. Subjects responded to CSI and MAT [17].

\subsection{Data analysis method}

Validity of CSI was evaluated using translation, construct and convergent validity and reliability was investigated by Cronbach's $\alpha$ using SPSS 23.

\subsection{Measures}

\subsubsection{Couple Satisfaction Index (CSI)}

$\mathrm{CSI}$ is a 32-item measure of relationship satisfaction. One global item uses a 7-point scale: "Please indicate the degree of happiness, all things considered, of your relationship", from $0=$ extremely unhappy to $6=$ perfect. Whereas the other 31 items used a variety of response anchors, all with 6-point scales. A sample item was "I feel I can confide in my partner about virtually anything". CSI scores correlate highly with other measures of relationship satisfaction (including all of the measures that initially contributed to its development) and discriminate between distressed and non-distressed relationships. The Cronbach's $\alpha$ coefficient for the whole scale was 0.98 [14].

\subsubsection{Marital Adjustment Test (MAT)}

MAT is the second most widely cited measure of satisfaction that was developed to optimally distinguish between well-adjusted and distressed relationships [17]. This measure has 15 items. The score of this scale ranges from 2 to 158, with low scores indicative of dissatisfaction and high scores of satisfaction. Validity and reliability of this scale have reported in Iranian studies $[18,19]$. The estimation of internal consistency using halving method has shown a reliability of 0.90 . The reliability calculated by Cronbach's $\alpha$ in many studies varies between 0.81 and 0.83 . The divergent validity of this tool has been confirmed in Sadeghi study [19].

\section{Results}

Descriptive statistical analysis showed the Mean (SD) score of CSI was 130(28). Also the Mean (SD) score of the MAT was 116(28).

\subsection{Validation}

To evaluate the validity of the scale, various methods such as construct and convergent validities were used.

\subsection{Construct validity}

After assessing the translation validity, exploratory and confirmatory factor analysis was employed to examine the construct validity. At first, the adequacy of sample size ( $\mathrm{N}=150$ ) was investigated using Kaiser-Meyer-Olkin (KMO) and Bartlett's sphericity tests. The KMO was 0.95 which was satisfactory, and the Bartlett's sphericity test was also meaningful. To perform exploratory analysis, at first, items which reduced the adequacy of the model data for exploratory factor analysis were evaluated using anti-image matrix. No item was excluded from 32-item questionnaire in this evaluation. In the exploratory factor analysis, the correspondence of the items with the extracted factors was evaluated through 150 observations using the main component and varimax rotation methods.

Exploratory factor analysis led to the identification of four factors with a cumulative variance of $71 \%$ which is a good index of exploratory factor analysis. The four factors were named "marital happiness", "warmth of the relationship", "being together" and "right choice". Table 1 resents the values. The results of the Scree diagram confirm the above results and show that 32 questions of the questionnaire can be reduced to 4 factors. These results can be seen in Figure 1.

Confirmatory factor analysis (Figure 2) was performed using Maximum Likelihood Estimation (MLE) method and Chi-square test. Since the Chi-square statistic measures the difference between the observed and estimated matrices, a significance level above 0.08 is considered as the confirmation of the assumed model and factor analysis. As presented in Table 2, the goodness of fit indices are well within the acceptable range. Therefore, confirmatory factor analysis also supports the construct validity of the questionnaire.

\subsection{Convergent validity}

To evaluate convergent validity, the correlation between the scores obtained from the CSI and Locke- 
Table 1. Factor loading coefficients of exploratory factor analysis

\begin{tabular}{|c|c|c|c|c|}
\hline \multirow{2}{*}{ Measures } & \multicolumn{4}{|c|}{ Factors } \\
\hline & Marital Happiness & Warmth of the Relationship & Being Together & Right Choice \\
\hline Variance percentage & 29.74 & 19.48 & 11.41 & 6.59 \\
\hline Cronbach's $\alpha$ (96\%) & 0.97 & 0.94 & 0.70 & 0.71 \\
\hline 1 & 0.771 & & & \\
\hline 2 & & & 0.72 & \\
\hline 3 & & & 0.57 & \\
\hline 4 & 0.60 & & & \\
\hline 5 & 0.61 & & & \\
\hline 6 & & & & 0.51 \\
\hline 7 & 0.81 & & & \\
\hline 8 & 0.81 & & & \\
\hline 9 & 0.87 & & & \\
\hline 10 & & & & 0.86 \\
\hline 11 & 0.85 & & & \\
\hline 12 & 0.79 & & & \\
\hline 13 & 0.70 & & & \\
\hline 14 & 0.69 & & & \\
\hline 15 & & & & 0.82 \\
\hline 16 & 0.72 & & & \\
\hline 17 & 0.71 & & & \\
\hline 18 & 0.80 & & & \\
\hline 19 & 0.84 & & & \\
\hline 20 & 0.75 & & & \\
\hline 21 & 0.79 & & & \\
\hline 22 & 0.84 & & & \\
\hline 23 & 0.70 & & & \\
\hline 24 & 0.61 & & & \\
\hline 25 & & & 0.67 & \\
\hline 26 & 0.78 & & & \\
\hline 27 & & 0.86 & & \\
\hline 28 & 0.69 & & & \\
\hline 29 & & 0.89 & & \\
\hline 30 & 0.77 & & & \\
\hline 31 & & 0.88 & & \\
\hline 32 & 0.78 & & & \\
\hline
\end{tabular}




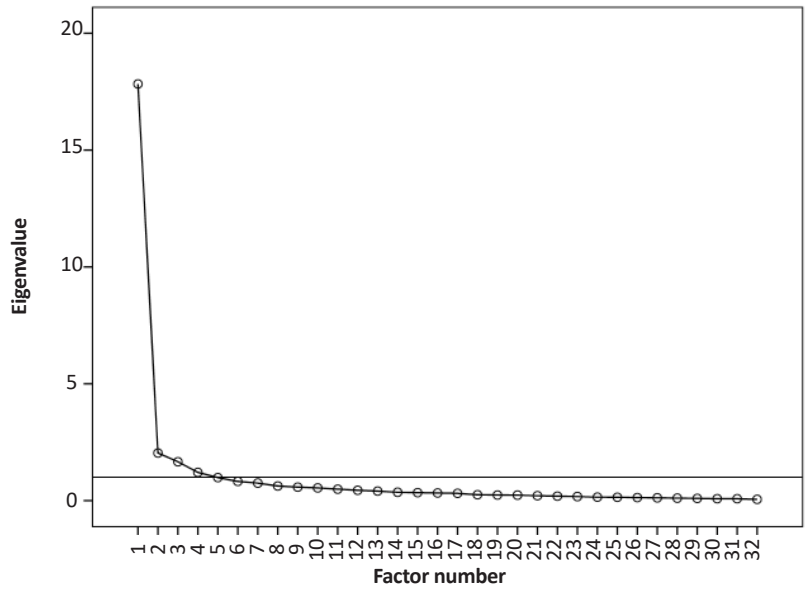

Figure 1. Characteristics of the factors extracted from questionnaire questions

Wallace MAT was investigated. Considering the high correlation between the scores of these two scales and their statistical significance, the convergent validity of couple's satisfaction index was confirmed. The results are presented in Table 3. Reliability The reliability of CSI was evaluated using Cronbach's $\alpha$. The Cronbach's $\alpha$ of the whole scale was 0.96 and higher than 0.70 in each subscale, indicating a good internal consistency of the questionnaire. These results are presented in Table 4.

\section{Discussion}

The purpose of this study was to introduce a precision instrument for measuring marital satisfaction in Iran. Accordingly, psychometric characteristics of CSI was

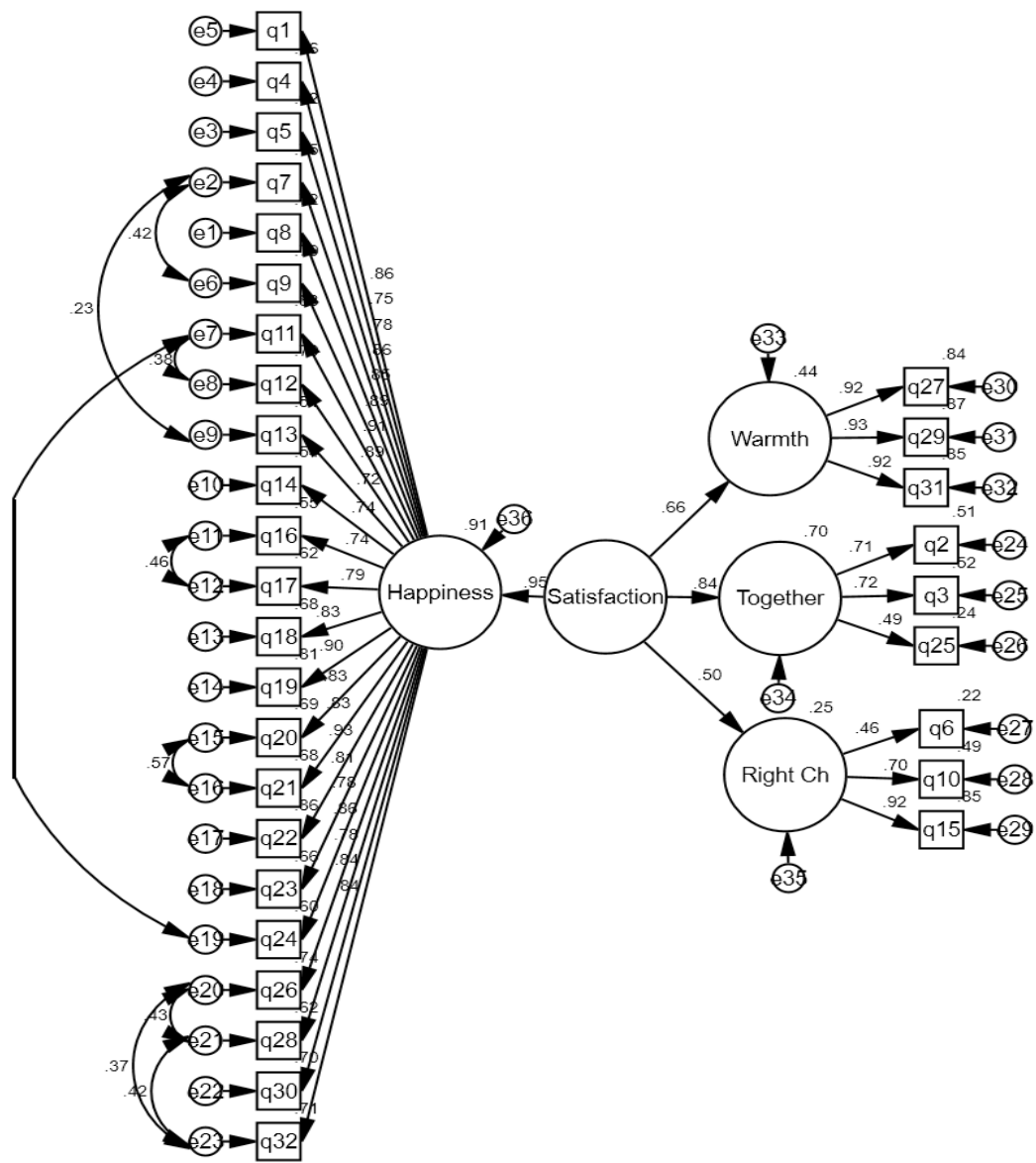

Figure 2. Factor model fitted for couple satisfaction index data 
Table 2. Results of confirmatory factor analysis of couple satisfaction index items

\begin{tabular}{cccccc}
\hline RMSEA & PGFI & $\mathbf{x}^{2} / \mathbf{d f}$ & CFI & df & $\mathbf{x}^{2}$ \\
\hline 0.07 & 0.649 & 1.73 & 0.928 & 452 & 783.84 \\
$<0.08$ & Up to 0.6 & $<2$ & Up to 0.9 & & \\
\hline
\end{tabular}

AJNPP

Table 3. Correlation results of couples' satisfaction Index and Marital Adjustment Test

\begin{tabular}{ccc}
\hline Scales & Correlation \\
\hline Marital happiness & $0.91<$ \\
Warmth of the relationship & 48.0 & $<0.001<$ \\
Being together & 0.64 \\
Right choice & $0.56<0.001<0.001<$ \\
Total & $0.90<$
\end{tabular}

AJNPP

evaluated in Iranian students. The results of exploratory and confirmatory factor analysis show that the scale is valid and acceptable in the Iranian student society. Although in original version of CSI, all items of the questionnaire were loaded to one factor, the present study showed four factor for marital satisfaction in Iranian society. These factors are "marital happiness", "warmth of relationship", "being together" and "right choice". According to the items, "marital happiness" indicates internal happiness and feeling pleasure in couple relationship, "warmth of relationship" indicates closeness and intimacy with spouse, "being together" indicate the amount of time that couple spend together and "right choice" indicates assurance in choosing spouse and no feelings of regret in marriage. The analysis shows that "marital happiness", "warmth of relationship", "being together", and "right choice" explain respectively about
$30 \%, 20 \%, 11 \%$ and $7 \%$ of variance of marital satisfaction in Iranian student couples.

The results of the convergent validity indicate that all factors of the CSI-32 are highly (90\%) correlated with MAT that indicates appropriate convergent validity. These results correspond with the findings of earlier studies $[12,14,20]$. In addition, the reliability of CSI-32 was assessed using internal consistency method. The results show that $\mathrm{CSI}$ is highly reliable in the students' population. The Cronbach's $\alpha$ coefficient value shows a high internal consistency between items. This finding is consistent with other studies findings [14, 20-22]. According to the results, CSI-32 has appropriate psychometric characteristics in Iranian society and can be used to measure marital satisfaction since there is no longer any uncertainty about its efficiency.

Table 4. Results of reliability (Cronbach's $\alpha$ ) of couples' satisfaction index and its factors

\begin{tabular}{cc}
\hline Factors & Cronbach's $\boldsymbol{\alpha}$ \\
\hline Marital happiness & 0.97 \\
\hline Warmth of the relationship & 0.94 \\
Being together & 0.70 \\
Right choice & 0.71 \\
Total & 0.96 \\
\hline
\end{tabular}


Marital satisfaction was initially thought to be represented by adjustment to spouse, marriage and marital relationship. Today marital satisfaction is recognized as a person's subjective experience of the relationship $[23,24]$. Four dimensional factor structure of CSI-32 in the current study shows that although "marital happiness" and "warmth of relationship" explain 50\% of marital satisfaction, amount of time that couple spend together and assurance in choosing spouse are important for Iranian couples and has dedicated separate factors. This finding may suggest a more complicated marital satisfaction in Iranian couples and indicates the importance of cultural studies in intimate relationships literature [25].

In another study in Pakistan, researchers used CSI-4 and found significant co-variation between two items (degree of happiness in the relationship and do you have a warm and comfortable relationship with your partner?) [11]. It might be a function of the fact that in Asian countries unlike Western societies, happiness is more relational and is a product of warmth and comfort in relationships. Individuals feel more pleasure where the self is perceived as part of the whole relationship [26].

Fowers et al. demonstrated a strong correlation between CSI and Relationship Flourishing Scale (RFS) and pointed out that CSI is a hedonic measure of relationship that focuses less on the content of the relationship. While RFS focuses on substantive, eudaimonic aspects such as having shared goals, meaning and growth that emerge through specific relationship activities. Despite these differences, RFS has shared a $43 \%-71 \%$ of its variance with the CSI scale. This common variance corresponds to the eudaimonic theory, in which flourishing should include satisfaction and happiness [22].

Increasing the accuracy of marital satisfaction scales allows researchers to reduce the measurement error and increase their power without increasing the length of the questionnaires. Funk and Roger argued that using old scales for marital satisfaction is like using thermometers that only read temperatures in $5^{\circ}$ or $10^{\circ}$ intervals. While using CSI scales, researchers could be able to detect meaningful effects and differences between groups [14]. Since the CSI-32 measures perceived happiness instead of adjustment in marital relationships, it is helpful to be used in Relationship Enhancement (RE) studies and is an accurate scale for evaluating the effectiveness of these interventions $[16,27]$.

\section{Conclusion}

The results indicate that Persian version of the "Couples Satisfaction Index" has appropriate psychometric characteristics. Therefore, this measure can be confidently used in this field of research.

This study had some limitations; one of them was its study population that were students. It is suggested that the psychometric characteristics of CSI-32 be investigated in other populations so that it can be used for other groups. Also given that the participants were in early years of their marriage and most of them had no children, generalization of the results to other populations should be done with caution.

\section{Ethical Considerations}

\section{Compliance with ethical guidelines}

During data collection, participants were assured that their information will remain confidential and will be analyzed anonymously (code: 9-8, professional code of ethics: psychology and counseling organization of Islamic Republic of Iran, 2007). Furthermore, the ethics committee of Shahed University approved the research design to ensure that it is carried out in an ethical manner (IR.Shahed.REC.1396.71).

\section{Funding}

This paper was extracted from the PHD thesis in clinical psychology in shahed university Evaluating the Mediations of Effectiveness of Mindfulness Based Stress Reduction Program on increasing marital satisfaction in women By Fateme Forouzesh Yekta.

\section{Conflict of interest}

Authors have no conflict of interest.

\section{Acknowledgements}

The authors would like to thank all the participants for their valuable collaboration in this study.

\section{References}

[1] Gurman AS, Lebow JL, Snyder DK. Clinical Handbook of couple Therapy. New York: Guilford Press; 2015. 
[2] Diener E, Eunkook MS, Lucas RE, Smith HL. Subjective well-being: Three decades of progress. Psychological Bulletin. 1999; 125(2):276-303. [DOI:10.1037/0033-2909.125.2.276]

[3] Wade TJ, pevalin DJ. Marital transitions and mental health. Journal of Health and Social Behavior. 2004; 45(2):155-70. [DO I:10.1177/002214650404500203] [PMID]

[4] Dupre ME, Beck AN, Meadows SO. Marital trajectories and mortality among US adults. American Journal of Epidemiology. 2009; 170(5):546-55. [DOI:10.1093/aje/kwp194] [PMID] [PMCID]

[5] Waite L, Gallagher M. The case for marriage: Why married people are happier, Healthier and better off financially. New York: Random House; 2002.

[6] Gharibi M, Sanagouymoharer G, Yaghoubinia F. The relationship between quality of life with marital satisfaction in nurses in social security hospital in Zahedan. Global Journal of Health Science. 2016; 8(2):178-84. [PMID] [PMCID]

[7] South SC, Krueger RF. Marital satisfaction and physical health: Evidence for an orchid effect. Psychological Science. 2013, 24(3):373-8. [DOI:10.1177/0956797612453116] [PMID] [PMCID]

[8] Whisman MA, Uebelacker LA, Weinstock LM. Psychopathology and marital satisfaction: The importance of evaluating both partners. Journal of Consulting and Clinical Psychology. 2004; 72(5):830-8. [DOI:10.1037/0022-006X.72.5.830] [PMID]

[9] Wang Q, Wang D, Li C, Miller RB. Marital satisfaction and depressive symptoms among Chinese older couples. Aging \& Mental Health. 2014; 18(1):11-8. [DOI:10.1080/13607863.20 13.805730] [PMID]

[10] Amato PR. The consequences of divorce for adults and children. Journal of Marriage and Family. 2000; 62(4):1269-87. [DOI:10.1111/j.1741-3737.2000.01269.x]

[11] Qadir F, Khalid A, Haqqani S, Zill-e-Huma, Medhin G. The association of marital relationship and perceived social support with mental health of women in Pakistan. BMC Public Health. 2013; 13:1150. [PMID] [PMCID]

[12] Fincham FD, Rogge R. Understanding relationship quality: Theoretical challenges and new tools for assessment. Journal of Familiy Theory \& Review. 2010; 2(4):227-42. [DOI:10.1111/ j.1756-2589.2010.00059.x]

[13] Bradbery NT, Fincham DF, Beach RS. Research on the nature and determinants of marital satisfaction: A decade in review. Journal of Marriage and Family. 2000; 3(62):964-80 [DOI:10.1111/j.1741-3737.2000.00964.x]

[14] Funk JL, Rogge RD. Testing the ruler with item response theory: Increasing precision of measurement for relationship satisfaction with the couples satisfaction index. Journal of Family Psychology. 2007; 21(4):572-83. [DOI:10.1037/08933200.21.4.572] [PMID]

[15] Munro BH. Statistical methods for health care research. Philadelphia, Pennsylvania: Lippincott Williams \& Wilkins; 2005.

[16] Funk JL, Rogge R. The Couples Satisfaction Index (CSI). Michigan: Fetzer Institute; 2007.

[17] Locke HJ, Wallace KM. Short marital adjustment and prediction tests: Their reliability and validity. Marriage and Family Living. 1959; 21(3):251-55. [DOI:10.2307/348022]
[18] Ramezani N. [Comparison of resiliency in couples (Persian)] [MSc. thesis]. Tehran: Shahid Beheshti University; 2009.

[19] Sadeghi M. [Comparison of stiffness in couples Resilient Master's thesis Faculty of Education and Psychology Marital interactive pattern in Iranian culture and the effect of teaching culture-based communication skills on increasing the Adjustment of distressed couples (Persian)] [PhD thesis]. Tehran: Shahid Beheshti University; 2010.

[20] Graham JM, Diebels KJ, Barnow ZB. The reliability of relationship satisfaction: A reliability generalization metaanalysis. Journal of Family Psychology. 2011; 25(1):39-48. [DOI:10.1037/a0022441] [PMID]

[21] Lee S, Rogge RD, Reis HT. Assessing the seeds of relationship decay: Using implicit evaluations to detect the early stages of disillusionment. Psychological Science. 2010; 21(6):85764. [DOI:10.1177/0956797610371342] [PMID]

[22] Fowers BJ, Laurenceau JP, Penfield RD, Cohen LM, Lang $\mathrm{SF}$, Owenz MB et al. Enhancing relationship quality measurement: The development of the Relationship Flourishing Scale. Journal of Family Psychology. 2016; 30(8):997-1007. [DOI: 10.1037/fam0000263] [PMID]

[23] Roach AJ, Frazier LP, Bowden SR. The marital satisfaction scale: Development of a measure for intervention research. Journal of Marriage and Family. 1981; 43(3):537-46. [DOI:10.2307/351755]

[24] Sabatelli RM. Measurement Issues in Marital Research A Review and Critique of Contemporary Survey Instruments. Journal of Marriage and Family. 1988; 50(4):891-915 [DOI:10.2307/352102]

[25] Zaheri F, Dolatian M, Shariati M, Simbar M, Ebadi A, Azghadi SBH. Effective factors in marital satisfaction in perspective of Iranian women and men: A systematic review. Electronic Physician. 2016; 8(12):3369-77. [DOI:10.19082/3369] [PMID] [PMCID]

[26] Uchida Y, Norasakkunkit V, Kitayama S. Cultural constructions of happiness: Theory and emprical evidence. Journal of Happiness Studies. 2004; 5(3):223-39. [DOI:10.1007/ s10902-004-8785-9]

[27] Gambrel LE, Piercy FP. Mindfulness-based relationship education for couples expecting their first child-part 1: Arandomized mixed-methods program evaluation. Journal of Marital and Family Therapy. 2015; 41(1):5-24. [DOI:10.1111/ jmft.12066] [PMID] 